\title{
Determination of food group intakes in Irish teenagers aged 13-17 years
}

\author{
S. Doyle, J. Walton, E. M. Hannon and A. Flynn \\ Department of Food and Nutritional Science, University College Cork, Cork, Republic of Ireland
}

The objective of the present study was to determine the food group intakes in Irish teenagers. Analysis was based on the National Teens' Food Survey (NTFS), which was carried out between September 2005 and September 2006 to establish a database of habitual food and drink consumption in a representative sample of Irish teenagers aged 13-17 years. A $7 \mathrm{~d}$ semi-weighed food record was used to collect food intake data from 441 teenagers (224 males, 217 females). Analysis of dietary intake data was carried out using WISPC (Tinuviel Software, Llanfechell, Anglesey, UK), which is based on McCance and Widdowson's The Composition of Foods Sixth Edition ${ }^{(1)}$.

\begin{tabular}{|c|c|c|c|c|c|}
\hline & \multicolumn{2}{|c|}{ Population $(n$ 441) $(\mathrm{g} / \mathrm{d})$} & \multicolumn{3}{|c|}{ Consumers only $(\mathrm{g} / \mathrm{d})$} \\
\hline & Mean & SD & $\%$ consumers & Mean & SD \\
\hline Bread and rolls & 92 & 55 & 99 & 93 & 55 \\
\hline White bread andn rolls & 63 & 43 & 96 & 66 & 42 \\
\hline Wholemeal and brown breads and rolls & 20 & 39 & 48 & 41 & 48 \\
\hline Breakfast cereals & 47 & 62 & 84 & 56 & 63 \\
\hline 'Ready to eat' breakfast cereals & 31 & 32 & 81 & 38 & 32 \\
\hline Other breakfast cereals (including milk and water) & 16 & 56 & 15 & 110 & 106 \\
\hline Milk and milk products & 280 & 241 & 97 & 290 & 239 \\
\hline Whole milk & 206 & 232 & 82 & 253 & 232 \\
\hline Reduced-fat milk & 42 & 122 & 24 & 176 & 197 \\
\hline Yoghurt & 22 & 36 & 43 & 51 & 39 \\
\hline Fruit and fruit juices & 149 & 174 & 83 & 181 & 176 \\
\hline Fruit & 63 & 121 & 67 & 94 & 138 \\
\hline Fruit juices & 86 & 116 & 62 & 140 & 120 \\
\hline Vegetables and vegetable dishes & 61 & 53 & 92 & 67 & 52 \\
\hline Vegetables & 54 & 47 & 91 & 60 & 46 \\
\hline Meat and meat products & 160 & 78 & 98 & 163 & 75 \\
\hline Fresh meat & 44 & 36 & 88 & 50 & 36 \\
\hline Processed meat & 63 & 44 & 96 & 65 & 43 \\
\hline Potatoes and potato products & 139 & 77 & 99 & 140 & 77 \\
\hline Potatoes (e.g. boiled, mashed, baked) & 70 & 63 & 83 & 84 & 60 \\
\hline Chipped, fried and roasted potatoes & 62 & 50 & 93 & 67 & 49 \\
\hline Beverages & 790 & 424 & 100 & 790 & 424 \\
\hline Non-diet carbonated beverages & 185 & 189 & 82 & 225 & 186 \\
\hline Diet carbonated beverages & 21 & 65 & 18 & 121 & 108 \\
\hline Squashes, cordials and fruit juice drinks & 34 & 66 & 45 & 76 & 80 \\
\hline Sugars, confectionery, preserves and savouries & 52 & 37 & 99 & 53 & 37 \\
\hline Biscuits, cakes and pastries & 24 & 30 & 82 & 29 & 30 \\
\hline
\end{tabular}

On average, total intake of fruit and vegetables (two servings per d) was less than recommended (five servings per $d^{(2)}$ ). Several undesirable patterns of food intake were observed for bread (mainly white), meat (mainly processed), milk (mainly whole milk) and beverages (mainly with added sugar). The patterns of consumption of food groups may have implications for dietary intakes of fat, saturated fat, added sugar, salt and dietary fibre.

The project was funded by Irish Government under the National Development Plan 2000-2006.

1. Food Standards Agency (2002) McCance \& Widdowson's The Composition of Foods Sixth Edition. Cambridge: Royal Society of Chemistry.

2. World Health Organization (2003) Diet, Nutrition and the Prevention of Chronic Diseases. Report of a Joint WHO/FAO Expert Consultation. WHO Technical Report Series no. 916. Geneva: WHO. 